\title{
Advances and Challenges in Studying Type III Secretion Effectors of Attaching and Effacing Pathogens
}

\author{
Sabrina L. Slater and Gad Frankel* \\ MRC Centre for Molecular Bacteriology and Infection, Department of Life Sciences, Imperial College London, London, \\ United Kingdom
}

Keywords: enteropathogenic E. coli, EPEC, enterohaemorrhagic E. coli, EHEC, T3SS, effector, C. rodentium, machine learning

\section{INTRODUCTION}

Outbreaks of the diarrhoeal disease caused by enteropathogenic Escherichia coli (EPEC) and enterohaemorrhagic E. coli (EHEC) present a significant burden to public health in countries with low and high human development indices (HDIs) alike. Over the course of evolution, horizontal gene transfer events have expanded the $4.1 \mathrm{Mb}$ core genome of the human colonic commensal E. coli by $1 \mathrm{Mb}$, resulting in the emergence of pathogens (Croxen and Finlay, 2010; Clements et al., 2012). Each pathogenic strain is characterized by their unique virulence factor repertoire and clinical epidemiology (Nataro and Kaper, 1998; Gomes et al., 2016). EPEC causes infantile diarrhea in countries with a low HDI. Indeed, from 2007 to 2015 the World Health Organization (WHO) estimate 230,000 cases of death from diarrhoeal disease, of which EPEC was responsible for 16\%,

Edited by: Gunnar Neels Schroeder, Queen's University Belfast, United Kingdom

Reviewed by:

V. K. Viswanathan, University of Arizona, United States

*Correspondence:

Gad Frankel

g.frankel@imperial.ac.uk

Specialty section:

This article was submitted to

Bacteria and Host,

a section of the journal

Frontiers in Cellular and Infection

Microbiology

Received: 22 April 2020

Accepted: 04 June 2020

Published: 07 July 2020

Citation:

Slater SL and Frankel G (2020) Advances and Challenges in Studying

Type III Secretion Effectors of

Attaching and Effacing Pathogens.

Front. Cell. Infect. Microbiol. 10:337.

doi: 10.3389/fcimb.2020.00337 disproportionately affecting children under five (WHO, 2015). EHEC, on the other hand, is defined by its ability to produce Shiga toxins (Stx) (Melton-Celsa, 2014; Krause et al., 2018). Distinguishing between EPEC and EHEC is clinically important, as treatment of EHEC with antibiotics can incite Stx expression (Zhang et al., 2000) and consequently acute kidney failure, a sequela of haemolytic uremic syndrome (HUS) (Pacheco and Sperandio, 2012).

EPEC and EHEC are united in their ability to intimately adhere to human enterocytes, causing elongation and loss of microvilli, and the formation of actin-rich pedestals at the site of bacterial attachment (Finlay et al., 1992; Frankel and Phillips, 2008) As such, EPEC and EHEC are members of the attaching and effacing (A/E) family of pathogens, which also include E. albertii (Bhatt et al., 2019), the murine-restricted Citrobacter rodentium (Mullineaux-Sanders et al., 2019) and rabbit enteropathogenic E. coli (REPEC) (Milon et al., 1999). The formation of A/E lesions is facilitated by proteins encoded on the locus of enterocyte effacement (LEE), a largely conserved $35.6 \mathrm{~kb}$ pathogenicity island that encodes components of the Type 3 Secretion System (T3SS). The T3SS of $\mathrm{A} / \mathrm{E}$ pathogens is $\sim 3.5 \mathrm{MDa}$ and includes several elements. Its cytoplasmic complex is equipped with an ATPase (EscN), secretion regulators (SepL and SepD) and chaperones (such as CesT). A basal body spans the inner and outer membranes, tethering the sheathed extracellular EscF needle to EspA filaments (Knutton et al., 1998) and culminates in the translocation pore (comprising EspB and EspD) in the host membrane (reviewed by Slater et al., 2018). The integration of signals from the gut environment, the microbiome and chaperones facilitate T3SS assembly, and translocation of effector proteins from the bacterium directly into the host cytosol (McDaniel et al., 1995; Connolly et al., 2015; Furniss and Clements, 2017; Katsowich et al., 2017; Serapio-Palacios and Finlay, 2020).

The effectors of A/E pathogens are encoded on either the LEE, prophages or insertion elements. While all the effectors rely on an $\mathrm{N}$-terminal translocation sequence and specific chaperone-binding motifs to guide secretion (Deng et al., 2017; Slater et al., 2018; Wagner et al., 2018), their sequences are otherwise highly adapted to intercept specific host processes. Additionally, effector 
TABLE 1 | Reported repertoire of AVE effectors, their method of discovery and inferred role during infection.

\begin{tabular}{|c|c|c|}
\hline Effector & Discovery method & Inferred function during infection \\
\hline Cif & Transposon mutagenesis in rabbit ileal loop model & Promotes bacterial survival/ cell cycle arrest \\
\hline Tir/EspE & Anti-phosphotyrosine blotting & Host adherence, actin polymerisation and pyroptosis \\
\hline EspG & LEE inspection/ effector homology & Manipulates small GTPases \\
\hline EspH & LEE inspection & Cytoskeletal remodeling, inhibition of phagocytosis \\
\hline EspK & Transposon mutagenesis in calf model & Unknown \\
\hline EspL & Mass spectrometry (MS) of secreted proteins & Inhibits necroptosis \\
\hline EspM1/2 & MS of secreted proteins & Cytoskeletal remodeling \\
\hline EspN & MS of secreted proteins & Unknown \\
\hline EspO & MS of secreted proteins & Promotes tissue integrity by promoting IL-22 secretion \\
\hline EspW & MS of secreted proteins & Cytoskeletal remodeling \\
\hline EspX/NleL & MS of secreted proteins & Ligates ubiquitin \\
\hline EspY & MS of secreted proteins & Unknown \\
\hline EspZ/SepZ & Transposon mutagenesis in cell culture & Limits effector translocation \\
\hline Map & LEE inspection & Cytoskeletal remodeling, mitochondrial disruption and colonic oxygenisation \\
\hline $\mathrm{NleB}$ & MS of secreted proteins & Inhibits pro-inflammatory signaling and necroptosis \\
\hline $\mathrm{NleC}$ & MS of secreted proteins & NF-kB inhibition \\
\hline $\mathrm{NleD}$ & Transposon mutagenesis in bovine gastrointestinal tract model & MAPK signaling inhibition \\
\hline $\mathrm{NleE}$ & MS of secreted proteins & NF-kB inhibition \\
\hline $\mathrm{NleF}$ & MS of secreted proteins & Inhibits caspase- $4 / 8 / 9$ activity to limit cell death \\
\hline $\mathrm{NleG}$ & MS of secreted proteins & Ligates ubiquitin \\
\hline
\end{tabular}

functions can be antagonistic or cooperative (Shenoy et al., 2018), which taken together with their low abundance and continuous acquisition, underpins the challenge of identifying and studying effectors in a meaningful context.

Current research into the effector biology of $\mathrm{A} / \mathrm{E}$ pathogens can be considered in three phases: discovery, in vitro functional characterization, and defining the contribution of each effector to the pathogen's infection strategy in vivo. To date, 30 families of effectors have been identified in $\mathrm{A} / \mathrm{E}$ pathogens (Table 1). However, as with many pathogens, the rate of effector discovery has surpassed their biological characterization, and the contribution of many effectors to pathogenesis remains unknown. Here we highlight recent advances in technical and conceptual approaches to characterize effectors in $\mathrm{A} / \mathrm{E}$ pathogens in the context of human disease.

\section{PREDICTING AND VERIFYING TRANSLOCATION SUBSTRATES}

Several resources have been developed to identify new effectors. Effector-encoding genes can be predicted in silico to varying degrees of accuracy (McDermott et al., 2011; Hobbs et al., 2016; Xue et al., 2019). These algorithms harness experimental knowledge of typical type III effector features, such as N-terminal enrichment of small polar amino acids (e.g., serine and threonine; Arnold et al., 2009), conservation of regulatory motifs upstream of the gene, a differing GC content to the rest of the genome, lack of gene homology to non-T3SS-encoding strains, and gene proximity to known effectors (Teper et al., 2016). Indeed, many novel type III effectors have been identified and validated using algorithm-based approaches, including Pseudomonas syringae and P. fluorescens (Vinatzer et al., 2005; Samudrala et al., 2009), Ralstonia spp. (Sabbagh et al., 2019), S. Typhimurium (Samudrala et al., 2009), Chlamydia trachomatis and C. psittaci (Hovis et al., 2013), Xanthomonas euvesicatoria (Teper et al., 2016) and Pantoea agglomerans (Nissan et al., 2018).

Despite these successes, algorithm-based approaches have yet to be applied to $\mathrm{A} / \mathrm{E}$ genomes. Instead, effectors in A/E pathogens were historically discovered through manually curating pathogenicity island genes and mutagenesis screening (Dziva et al., 2004; Mundy et al., 2004; Kanack et al., 2005), homology searches to other T3SS effectors in different species 
(Bulgin et al., 2009; Petty et al., 2010), mRNA profiling during infection (Dahan et al., 2005), and peptide discovery mass spectrometry (MS) of secreted proteins, notably in combination with $2 \mathrm{D}$ gel electrophoresis and effector hypersecretion mutants (Kresse et al., 2000; Creasey et al., 2003; Deng et al., 2004, 2010, 2012; Gruenheid et al., 2004; O'Connell et al., 2004; Tobe et al., 2006; Orton et al., 2013). Moving forward, the employment of techniques that do not rely on homology offer less bias and are therefore preferable. Additionally, A/E pathogens that encode a second functional T3SS (named ETT2) may also secrete its own cognate effectors (Fox et al., 2020), and secretion substrates could be shared between the two T3SSs, as there is evidence for regulatory crossover (Zhang et al., 2004; Luzader et al., 2016).

Once identified, the T3SS-dependent translocation of candidate effectors must be experimentally confirmed. A common approach, developed in 2004 by Charpentier and Oswald, is to C-terminally tag the effector with the TEM-1 $\beta$-lactamase and infect CCF2-loaded cells (Charpentier and Oswald, 2004); alternative and refined protocols have since been developed that decrease the tag size, minimize cell toxicity and offer single cell resolution. Collectively, these approaches benefit from their capacity to support different modes of analysis depending on the infection setup, such as enzymatic assays, optical readouts in a 96-well plate, flow cytometry and immunofluorescence microscopy (Mills et al., 2008; Miyake et al., 2008; Gawthorne et al., 2016; O’Boyle et al., 2018).

\section{IN VITRO CHARACTERIZATION OF THE EFFECTORS}

Approaches to characterize the role of each new effector during infection are ever-developing. At its most fundamental, effector functionality can be investigated under overexpression conditions in vitro, where amenable cells are transfected for ectopic effector expression or microinjected with purified protein. Overexpression protocols can provide readouts for drastic visual phenotypes, such as the radical cytoskeletal rearrangements resulting from the transfection of EspV (Arbeloa et al., 2011). Non-mammalian eukaryotic systems such as Saccharomyces cerevisiae have also been instrumental in the definition of eukaryotic interaction partners for $\mathrm{A} / \mathrm{E}$ effectors (Hardwidge et al., 2004; Popa et al., 2016), as well as delineating interfaces for substrate interaction and catalytic residues (Blasche et al., 2013, 2014; Sandu et al., 2017).

These approaches, however, share a common weakness: effectors localize differently when not natively translocated through the injectisome. As such, the infection of appropriate mammalian cells (i.e., colonic epithelial cells) with bacteria translocating a tagged effector protein can provide a more physiologically relevant readout for effector localization. Indeed, native expression of a tagged effector is readily achievable by introducing a C-terminal tag onto the chromosome for effector visualization by immunofluorescence, or for use in tandem with co-immunoprecipitation and/or MS to probe for host protein interactors upon infection. Chromosomal manipulation by triparental conjugation works efficiently in $\mathrm{A} / \mathrm{E}$ pathogens and other enteric pathogens (Mullineaux-Sanders et al., 2017; Watson et al., 2019; Wong et al., 2019). This conjugation protocol can similarly be used to generate scarless isogenic effector mutants in lieu of traditional gene disruption with antibiotic resistance cassettes or transposon elements (Cepeda-Molero et al., 2017).

\section{DEFINING ROLES FOR THE EFFECTORS DURING INFECTION}

Despite the ease of culturing, transfection and microscopy offered by non-polarized and non-colonic cells, the integrated use of more relevant models circumvents cell-line-specific phenotypes. A shift in practice toward more native models for infection is therefore evolving, using differentiated, polarized colonic cell lines, explants and organoids, primary tissues and laboratory animals (Carvalho et al., 2005; Law et al., 2013; Lewis et al., 2016; Cepeda-Molero et al., 2017). Increasingly, infections with $\mathrm{A} / \mathrm{E}$ pathogens are also modeled in immuneassociated cells, whose distinctive protein expression profiles allows researchers to probe the impact of effector delivery on immune-specific pathways (Pearson et al., 2017; Goddard et al., 2019), providing an alternative insight into the impact of effectors in human infection.

One particularly useful model for probing effector function is the infection of mice with C. rodentium. C. rodentium is a natural murine pathogen which causes transmissible colonic crypt hyperplasia $(\mathrm{CCH})$ and $\mathrm{A} / \mathrm{E}$ lesions that are indistinguishable from those cause by EPEC and EHEC in humans (Barthold et al., 1978). Critically, C. rodentium shares $67 \%$ homology with EPEC and EHEC genomes, most notably in the LEE (Petty et al., 2010, 2011), making it an invaluable tool for the study of the role of the T3SS and its cognate effectors in vivo (Mundy et al., 2005; Borenshtein et al., 2008; Collins et al., 2014; Mullineaux-Sanders et al., 2019).

The contribution of single or multiple effectors to pathogenesis can be assayed via infection with $C$. rodentium deletion or point mutants (Crepin et al., 2016). Key to revealing novel and physiological phenotypes is the selection of an appropriate mouse strain, or knock-out mice (Simmons et al., 2002; Zheng et al., 2008; Carson et al., 2019). To highlight some examples, the mouse model has delineated Tir, NleA and NleB as essential effectors for efficient colonization (Deng et al., 2003; Mundy et al., 2004; Kelly et al., 2006), demonstrated the impact of individual effectors deletions on host physiology, such as EspO and EspS impacting CCH (Berger et al., 2018; Connolly et al., 2018), and substantiated in vitro data indicating Map impacts colonic oxygen availability through mitochondrial disruption (Berger et al., 2017). Recently, mouse-specific differences in infection signatures have been identified through RNAseq and proteomics (Kang et al., 2018; Carson et al., 2019); it remains to be seen whether these differences are fine-tuned by the synergistic action of the effectors.

There are important genetic differences between C. rodentium and human A/E pathogens. While C. rodentium encodes a type IV pilus named colonization factor Citrobacter (CFC), which is related to the EPEC bundle forming pilus (BFP) (Mundy 
et al., 2003), it does not encode some strain-specific effectors, nor does it express the Shiga toxin or a flagellum, and it likely benefits from mouse-specific host adaptations. Nevertheless, modifications to this model can be implemented to investigate specific aspects of infection by human A/E pathogens, such as HUS and diarrhea (Vallance et al., 2003; Mallick et al., 2012), and drawing parallels from $C$. rodentium studies offers invaluable insight into human infections.

At the other end of the spectrum, the use of minimal effector models should prove instrumental for delineating the complex interplay between effectors, where the creation and complementation of isogenic strains cannot. As has been employed for Yersinia pestis (Palace et al., 2018), all known effectors were recently removed from the EPEC E2348/69 genome to investigate the contribution of select effectors and intact pathogenicity islands to $\mathrm{A} / \mathrm{E}$ lesion formation on the human intestinal mucosa ex vivo, confirming that while Tir is essential, it is not sufficient and other elusive effectors are required (Cepeda-Molero et al., 2017). Undoubtedly the same approach would be of great use for other T3SS-encoding pathogens. Building on the decades of fundamental biochemical research into individual effector proteins, the mutation of clusters of effectors with similar functions in vitro should also be considered.

Despite the wealth of technical and biological knowledge unearthed over the last two decades, the synergies and redundancies in the function of the effectors hamper the comparison of in vitro research to in vivo scenarios. However, large-scale sequencing efforts of human pathogenic E. coli isolates have revealed the correlation between the presence of effectors, and other virulence factors, and the severity of human pathology through comparative genomics (Donnenberg et al., 2015; Hazen et al., 2016). This can be extended to assaying the prevalence of effectors in strains from different environments (Xu et al., 2017). Although challenging to integrate, these datasets offer unparalleled insight into the relative importance of effector proteins during human infection. Finally, following translocation, effectors form tight interaction networks. As clinical EPEC and EHEC isolates encode strain-specific effector gene combinations, it would be interesting to test the robustness of these networks in vivo. This will offer insight into the virulence potential of alternative effector combinations present

\section{REFERENCES}

Arbeloa, A., Oates, C. V., Marchès, O., Hartland, E. L., and Frankel, G. (2011). Enteropathogenic and enterohemorrhagic Escherichia coli type III secretion effector EspV induces radical morphological changes in eukaryotic cells. Infect. Immun. 79, 1067-1076. doi: 10.1128/IAI.01003-10

Arnold, R., Brandmaier, S., Kleine, F., Tischler, P., Heinz, E., Behrens, S., et al. (2009). Sequence-based prediction of type III secreted proteins. PLoS Pathog. 5:e1000376. doi: 10.1371/journal.ppat.1000376

Barthold, S. W., Coleman, G. L., Jacoby, R. O., Livstone, E. M., and Jonas, A. M. (1978). Transmissible murine colonic hyperplasia. Vet. Pathol. 15, 223-236. doi: $10.1177 / 030098587801500209$ in clinical isolates. C. rodentium provides an ideal model to address this.

\section{CONCLUSIONS AND FUTURE PERSPECTIVES}

With technological advances, our conceptual approaches must keep up. For example, moving beyond the idea that effectors act exclusively once translocated has illuminated greater functionality for $C$. rodentium $\mathrm{NleB}$, which was recently demonstrated to GlcNAcylate an intrabacterial glutathione synthase GshB to promote bacterial survival (El Qaidi et al., 2020); other effectors with enzymatic functions may also have intrabacterial targets. In the same vein, addressing effector functionality in a top-down fashion (from mammalian phenotype to bacterial genotype) has recently unveiled both a unique mode of EPEC-induced inflammatory cell death and a further role for Tir during infection (Goddard et al., 2019).

Effector proteins exhibit fascinating diversity and specificity. Consequently, their study is warranted not only by their importance in human disease. Effectors can demonstrate firstin-class functions, the characterization of which broadens our understanding of protein biochemistry. Additionally, as effectors have witnessed the complexity of eukaryotic signaling cascades for considerably longer than modern researchers, they offer a unique insight into the breadth of function our own cells.

\section{AUTHOR CONTRIBUTIONS}

SS and GF wrote the manuscript. All authors listed have made a substantial, direct and intellectual contribution to the work, and approved it for publication.

\section{FUNDING}

SS acknowledges funding from the BBSRC DTP No. 1655054 related to $\mathrm{BB} / \mathrm{M} 011178 / 1$. GF is supported by grants from the MRC and the Wellcome Trust.

\section{ACKNOWLEDGMENTS}

We thank Caroline Mullineaux-Sanders for critical reading of the manuscript. Fischer, M., et al. (2017). Citrobacter rodentium Subverts ATP flux and cholesterol homeostasis in intestinal epithelial cells in vivo. Cell Metab. 26, 738-752. doi: 10.1016/j.cmet.2017.09.003

Berger, C. N., Crepin, V. F., Roumeliotis, T. I., Wright, J. C., Serafini, N., PevsnerFischer, M., et al. (2018). The Citrobacter rodentium type III secretion system effector EspO affects mucosal damage repair and antimicrobial responses. PLoS Pathog. 14, 1-23. doi: 10.1371/journal.ppat.1007406

Bhatt, S., Egan, M., Critelli, B., Kouse, A., Kalman, D., and Upreti, C. (2019). The evasive enemy: Insights into the virulence and epidemiology of the emerging attaching and effacing pathogen escherichia albertii. Infect. Immun. 87, 1-15. doi: 10.1128/IAI.00254-18 
Blasche, S., Arens, S., Ceol, A., Siszler, G., Schmid, M. A., Häuser, R., et al. (2014). The EHEC-host interactome reveals novel targets for the translocated intimin receptor. Sci. Rep. 4, 22-26. doi: 10.1038/srep07531

Blasche, S., Mörtl, M., Steuber, H., Siszler, G., Nisa, S., Schwarz, F., et al. (2013). The E. coli effector protein NleF is a caspase inhibitor. PLoS ONE 8:e58937. doi: 10.1371/journal.pone.0058937

Borenshtein, D., McBee, M. E., and Schauer, D. B. (2008). Utility of the Citrobacter rodentium infection model in laboratory mice. Curr. Opin. Gastroenterol. 24, 32-37. doi: 10.1097/MOG.0b013e3282f2b0fb

Bulgin, R. R., Arbeloa, A., Chung, J. C. S., and Frankel, G. (2009). EspT triggers formation of lamellipodia and membrane ruffles through activation of Rac-1 and Cdc42. Cell. Microbiol. 11, 217-229. doi: 10.1111/j.1462-5822.2008.01248.x

Carson, D., Barry, R., Hopkins, E. G. D., Roumeliotis, T. I., García-Weber, D., Mullineaux-Sanders, C., et al. (2019). Citrobacter rodentium induces rapid and unique metabolic and inflammatory responses in mice suffering from severe disease. Cell. Microbiol. 22, 1-17. doi: $10.1111 / \mathrm{cmi} .13126$

Carvalho, H. M., Teel, L. D., Goping, G., and O’Brien, A. D. (2005). A threedimensional tissue culture model for the study of attach and efface lesion formation by enteropathogenic and enterohaemorrhagic Escherichia coli. Cell. Microbiol. 7, 1771-1781. doi: 10.1111/j.1462-5822.2004.00594.x

Cepeda-Molero, M., Berger, C. N., Walsham, A. D. S., Ellis, S. J., Wemyss-Holden, S., Schüller, S., et al. (2017). Attaching and effacing (A/E) lesion formation by enteropathogenic E. coli on human intestinal mucosa is dependent on non-LEE effectors. PLOS Pathog. 13:e1006706. doi: 10.1371/journal.ppat.1006706

Charpentier, X., and Oswald, E. (2004). Identification of the secretion and translocation domain of the enteropathogenic and enterohemorrhagic. $J$. Bacteriol. 186, 5486-5495. doi: 10.1128/JB.186.16.5486-5495.2004

Clements, A., Young, J. C., Constantinou, N., and Frankel, G. (2012). Infection strategies of enteric pathogenic Escherichia coli. Gut Microbes 3, 71-87. doi: $10.4161 /$ gmic. 19182

Collins, J. W., Keeney, K. M., Crepin, V. F., Rathinam, V. A. K., Fitzgerald, K. A., Finlay, B. B., et al. (2014). Citrobacter rodentium: infection, inflammation and the microbiota. Nat. Rev. Microbiol. 12, 612-623. doi: 10.1038/nrmicro3315

Connolly, J. P. R., Brett Finlay, B., and Roe, A. J. (2015). From ingestion to colonization: The influence of the host environment on regulation of the LEE encoded type III secretion system in enterohaemorrhagic Escherichia coli. Front. Microbiol. 6:568. doi: 10.3389/fmicb.2015.00568

Connolly, J. P. R., Slater, S. L., O’Boyle, N., Goldstone, R. J., Crepin, V. F., RuanoGallego, D., et al. (2018). Host-associated niche metabolism controls enteric infection through fine-tuning the regulation of type 3 secretion. Nat. Commun. 9:4187. doi: 10.1038/s41467-018-06701-4

Creasey, E. A., Delahay, R. M., Daniell, S. J., and Frankel, G. (2003). Yeast two-hybrid system survey of interactions between LEE-encoded proteins of enteropathogenic Escherichia coli. Microbiology 149, 2093-2106. doi: $10.1099 /$ mic.0.26355-0

Crepin, V. F., Collins, J. W., Habibzay, M., and Frankel, G. (2016). Citrobacter rodentium mouse model of bacterial infection. Nat. Protoc. 11, 1851-1876. doi: $10.1038 /$ nprot.2016.100

Croxen, M. A., and Finlay, B. B. (2010). Molecular mechanisms of Escherichia coli pathogenicity. Nat. Rev. Microbiol. 8, 26-38. doi: 10.1038/nrmicro2265

Dahan, S., Wiles, S., La Ragione, R. M., Best, A., Woodward, M. J., Stevens, M. P., et al. (2005). EspJ is a prophage-carried type III effector protein of attaching and effacing pathogens that modulates infection dynamics. Infect. Immun. 73, 679-686. doi: 10.1128/IAI.73.2.679-686.2005

Deng, W., De Hoog, C. L., Yu, H. B., Li, Y., Croxen, M. A., Thomas, N. A., et al. (2010). A comprehensive proteomic analysis of the type III secretome of Citrobacter rodentium. J. Biol. Chem. 285, 6790-6800. doi: 10.1074/jbc.M109.086603

Deng, W., Marshall, N. C., Rowland, J. L., McCoy, J. M., Worrall, L. J., Santos, A. S., et al. (2017). Assembly, structure, function and regulation of type III secretion systems. Nat. Rev. Microbiol. 15, 323-337. doi: 10.1038/nrmicro.2017.20

Deng, W., Puente, J. L., Gruenheid, S., Li, Y., Vallance, B. A., Vázquez, A., et al. (2004). Dissecting virulence: Systematic and functional analyses of a pathogenicity island. Proc. Natl. Acad. Sci. U.S.A. 101, 3597-3602. doi: 10.1073/pnas.0400326101

Deng, W., Vallance, B. A., Li, Y., Puente, J. L., and Finlay, B. B. (2003). Citrobacter rodentium translocated intimin receptor (Tir) is an essential virulence factor needed for actin condensation, intestinal colonization and colonic hyperplasia in mice. Mol. Microbiol. 48, 95-115. doi: 10.1046/j.1365-2958.2003.03429.x

Deng, W., Yu, H. B., de Hoog, C. L., Stoynov, N., Li, Y., Foster, L. J., et al. (2012). Quantitative proteomic analysis of type iii secretome of enteropathogenic Escherichia coli reveals an expanded effector repertoire for attaching/effacing bacterial pathogens. Mol. Cell. Proteomics 11, 692-709. doi: 10.1074/mcp.M111.013672

Donnenberg, M. S., Hazen, T. H., Farag, T. H., Panchalingam, S., Antonio, M., Hossain, A., et al. (2015). Bacterial factors associated with lethal outcome of enteropathogenic Escherichia coli infection: genomic case-control studies. PLoS Negl. Trop. Dis. 9:e0003791. doi: 10.1371/journal.pntd.0003791

Dziva, F., van Diemen, P. M., Stevens, M. P., Smith, A. J., and Wallis, T. S. (2004). Identification of Escherichia coli O157:H7 genes influencing colonization of the bovine gastrointestinal tract using signature-tagged mutagenesis. Microbiology 150, 3631-3645. doi: 10.1099/mic.0.27448-0

El Qaidi, S., Scott, N. E., Hays, M. P., Geisbrecht, B. V., Watkins, S., and Hardwidge, P. R. (2020). An intra-bacterial activity for a T3SS effector. Sci. Rep. 10:1073. doi: 10.1038/s41598-020-58062-y

Finlay, B. B., Rosenshine, I., Donnenberg, M. S., and Kaper, J. B. (1992) Cytoskeletal composition of attaching and effacing lesions associated with enteropathogenic Escherichia coli adherence to HeLa cells. Infect. Immun. 60, 2541-2543. doi: 10.1128/IAI.60.6.2541-2543.1992

Fox, S., Goswami, C., Holden, M., Connolly, J. P. R., Mordue, J., O’Boyle, N., et al. (2020). A highly conserved complete accessory Escherichia coli type III secretion system 2 is widespread in bloodstream isolates of the ST69 lineage. Sci. Rep. 10, 1-11. doi: 10.1038/s41598-020-61026-x

Frankel, G., and Phillips, A. D. (2008). Attaching effacing Escherichia coli and paradigms of Tir-triggered actin polymerization: getting off the pedestal. Cell. Microbiol. 10, 549-556. doi: 10.1111/j.1462-5822.2007.01103.x

Furniss, R. C. D., and Clements, A. (2017). Regulation of the locus of enterocyte effacement in attaching and effacing pathogens. J. Bacteriol. 200, e00336-17. doi: 10.1128/JB.00336-17

Gawthorne, J. A., Audry, L., McQuitty, C., Dean, P., Christie, J. M., Enninga, J., et al. (2016). Visualizing the translocation and localization of bacterial type III effector proteins by using a genetically encoded reporter system. Appl. Environ. Microbiol. 82, 2700-2708. doi: 10.1128/AEM.03418-15

Goddard, P. J., Sanchez-Garrido, J., Slater, S. L., Kalyan, M., Ruano-Gallego, D., Marchès, O., et al. (2019). Enteropathogenic Escherichia coli stimulates effector-driven rapid caspase-4 activation in human macrophages. Cell Rep. 27, 1008-1017. doi: 10.1016/j.celrep.2019.03.100

Gomes, T. A. T., Elias, W. P., Scaletsky, I. C. A., Guth, B. E. C., Rodrigues, J. F., Piazza, R. M. F., et al. (2016). Diarrheagenic Escherichia coli. Brazilian J. Microbiol. 47, 3-30. doi: 10.1016/j.bjm.2016.10.015

Gruenheid, S., Sekirov, I., Thomas, N. A., Deng, W., O’Donnell, P., Goode, D., et al. (2004). Identification and characterization of NleA, a non-LEE-encoded type III translocated virulence factor of enterohaemorrhagic Escherichia coli O157:H7. Mol. Microbiol. 51, 1233-1249. doi: 10.1046/j.1365-2958.2003.03911.x

Hardwidge, P. R., Rodriguez-Escudero, I., Goode, D., Donohoe, S., Eng, J., Goodlett, D. R., et al. (2004). Proteomic analysis of the intestinal epithelial cell response to enteropathogenic Escherichia coli. J. Biol. Chem. 279, 20127-20136. doi: 10.1074/jbc.M401228200

Hazen, T. H., Donnenberg, M. S., Panchalingam, S., Antonio, M., Hossain, A., Mandomando, I., et al. (2016). Genomic diversity of EPEC associated with clinical presentations of differing severity. Nat. Microbiol. 1:15014. doi: 10.1038/nmicrobiol.2015.14

Hobbs, C. K., Porter, V. L., Stow, M. L. S., Siame, B. A., Tsang, H. H., and Leung, K. Y. (2016). Computational approach to predict species-specific type III secretion system (T3SS) effectors using single and multiple genomes. BMC Genomics 17:1048. doi: 10.1186/s12864-016-3363-1

Hovis, K. M., Mojica, S., McDermott, J. E., Pedersen, L., Simhi, C., Rank, R. G., et al. (2013). Genus-optimized strategy for the identification of chlamydial type III secretion substrates. Pathog. Dis. 69, 213-222. doi: 10.1111/2049-632X.12070

Kanack, K. J., Crawford, J. A., Tatsuno, I., Karmali, M. A., and Kaper, J. B. (2005). SepZ/EspZ is secreted and translocated into HeLa cells by the enteropathogenic Escherichia coli type III secretion system. Infect. Immun. 73, 4327-4337. doi: 10.1128/IAI.73.7.4327-4337.2005 
Kang, E., Zhou, G., Yousefi, M., Cayrol, R., Xia, J., and Gruenheid, S. (2018). Loss of disease tolerance during Citrobacter rodentium infection is associated with impaired epithelial differentiation and hyperactivation of $\mathrm{T}$ cell responses. Sci. Rep. 8, 1-14. doi: 10.1038/s41598-017-17386-y

Katsowich, N., Elbaz, N., Pal, R. R., Mills, E., Kobi, S., Kahan, T., et al. (2017). Host cell attachment elicits posttranscriptional regulation in infecting enteropathogenic bacteria. Science 355, 735-739. doi: 10.1126/science.aah4886

Kelly, M., Hart, E., Mundy, R., Marchès, O., Wiles, S., Badea, L., et al. (2006). Essential role of the type III secretion system effector NleB in colonization of mice by Citrobacter rodentium. Infect. Immun. 74, 2328-2337. doi: 10.1128/IAI.74.4.2328-2337.2006

Knutton, S., Rosenshine, I., Pallen, M. J., Nisan, I., Neves, B. C., Bain, C., et al. (1998). A novel EspA-associated surface organelle of enteropathogenic Escherichia coli involved in protein translocation into epithelial cells. EMBO J. 17, 2166-2176. doi: 10.1093/emboj/17.8.2166

Krause, M., Barth, H., and Schmidt, H. (2018). Toxins of locus of enterocyte effacement-negative shiga toxin-producing Escherichia coli. Toxins (Basel). 10:241. doi: 10.3390/toxins 10060241

Kresse, A. U., Beltrametti, F., Muller, A., Ebel, F., and Guzman, C. A. (2000). Characterization of SepL of enterohemorrhagic Escherichia coli. J. Bacteriol. 182, 6490-6498. doi: 10.1128/JB.182.22.6490-6498.2000

Law, R. J., Gur-Arie, L., Rosenshine, I., and Brett Finlay, B. (2013). In vitro and in vivo model systems for studying enteropathogenic Escherichia coli infections. Cold Spring Harb. Perspect. Med. 3:a009977. doi: 10.1101/cshperspect.a0 09977

Lewis, S. B., Prior, A., Ellis, S. J., Cook, V., Chan, S. S. M., Gelson, W., et al. (2016). Flagellin induces $\beta$-defensin 2 in human colonic Ex vivo infection with enterohemorrhagic Escherichia coli. Front. Cell. Infect. Microbiol. 6:68. doi: 10.3389/fcimb.2016.00068

Luzader, D. H., Willsey, G. G., Wargo, M. J., and Kendall, M. M. (2016). The ETT2-encoded regulator EtrB modulates enterohemorrhagic Escherichia coli virulence gene expression. Infect. Immun. 84, 2555-2565. doi: 10.1128/IAI.00407-16

Mallick, E. M., McBee, M. E., Vanguri, V. K., Melton-Celsa, A. R., Schlieper, K., Karalius, B. J., et al. (2012). A novel murine infection model for Shiga toxin-producing Escherichia coli. J. Clin. Invest. 122, 4012-4024. doi: 10.1172/JCI62746

McDaniel, T. K., Jarvis, K. G., Donnenberg, M. S., and Kaper, J. B. (1995). A genetic locus of enterocyte effacement conserved among diverse enterobacterial pathogens. Proc. Natl. Acad. Sci. U.S.A. 92, 1664-1668. doi: 10.1073/pnas.92.5.1664

McDermott, J. E., Corrigan, A., Peterson, E., Oehmen, C., Niemann, G., Cambronne, E. D., et al. (2011). Minireview: computational prediction of type III and IV secreted effectors in gram-negative bacteria. Infect. Immun. 79, 23-32. doi: 10.1128/IAI.00537-10

Melton-Celsa, A. R. (2014). Shiga toxin (Stx) classification, structure, and function. Microbiol. Spectr. 2, 1-13. doi: 10.1128/microbiolspec.EHEC-0024-2013

Mills, E., Baruch, K., Charpentier, X., Kobi, S., and Rosenshine, I. (2008). Real-time analysis of effector translocation by the type III secretion system of enteropathogenic Escherichia coli. Cell Host Microbe 3, 104-113. doi: 10.1016/j.chom.2007.11.007

Milon, A., Oswald, E., and De Rycke, J. (1999). Rabbit EPEC: a model for the study of enteropathogenic Escherichia coli. Vet. Res. 30, 203-219.

Miyake, M., Sakane, S., Kobayashi, C., Hanajima-Ozawa, M., Fukui, A., Kamitani, S., et al. (2008). A colorimetric assay for studying effector secretion through the bacterial type III secretion system. FEMS Microbiol. Lett. 278, 36-42. doi: 10.1111/j.1574-6968.2007.00943.x

Mullineaux-Sanders, C., Collins, J. W., Ruano-Gallego, D., Levy, M., PevsnerFischer, M., Glegola-Madejska, I. T., et al. (2017). Citrobacter rodentium relies on commensals for colonization of the colonic mucosa. Cell Rep. 21, 3381-3389. doi: 10.1016/j.celrep.2017.11.086

Mullineaux-Sanders, C., Sanchez-Garrido, J., Hopkins, E. G. D., Shenoy, A. R., Barry, R., and Frankel, G. (2019). Citrobacter rodentium-host-microbiota interactions: immunity, bioenergetics and metabolism. Nat. Rev. Microbiol. 17, 701-715. doi: 10.1038/s41579-019-0252-z

Mundy, R., MacDonald, T. T., Dougan, G., Frankel, G., and Wiles, S. (2005). Citrobacter rodentium of mice and man. Cell. Microbiol. 7, 1697-1706. doi: $10.1111 /$ j.1462-5822.2005.00625.x
Mundy, R., Petrovska, L., Smollett, K., Simpson, N., Wilson, R. K., Yu, J., et al. (2004). Identification of a novel citrobacter rodentium type III secreted protein, espi, and roles of this and other secreted proteins in infection. Infect. Immun. 72, 2288-2302. doi: 10.1128/IAI.72.4.2288-2302.2004

Mundy, R., Pickard, D., Wilson, R. K., Simmons, C. P., Dougan, G., and Frankel, G. (2003). Identification of a novel type IV pilus gene cluster required for gastrointestinal colonization of Citrobacter rodentium. Mol. Microbiol. 48, 795-809. doi: 10.1046/j.1365-2958.2003.03470.x

Nataro, J. P., and Kaper, J. B. (1998). Diarrheagenic Escherichia coli. Clin. Microbiol. Rev. 11, 142-201. doi: 10.1128/CMR.11.1.142

Nissan, G., Gershovits, M., Morozov, M., Chalupowicz, L., Sessa, G., ManulisSasson, S., et al. (2018). Revealing the inventory of type III effectors in Pantoea agglomerans gall-forming pathovars using draft genome sequences and a machine-learning approach. Mol. Plant Pathol. 19, 381-392. doi: $10.1111 / \mathrm{mpp} .12528$

O'Boyle, N., Connolly, J. P. R., and Roe, A. J. (2018). Tracking elusive cargo: illuminating spatio-temporal Type 3 effector protein dynamics using reporters. Cell. Microbiol. 20, 1-9. doi: 10.1111/cmi.12797

O'Connell, C. B., Creasey, E. A., Knutton, S., Elliott, S., Crowther, L. J., Luo, W., et al. (2004). SepL, a protein required for enteropathogenic Escherichia coli type III translocation, interacts with secretion component SepD. Mol. Microbiol. 52, 1613-1625. doi: 10.1111/j.1365-2958.2004.04101.x

Orton, D. J., Arsenault, D. J., Thomas, N. A., and Doucette, A. A. (2013). GELFrEE fractionation combined with mass spectrometry for proteome analysis of secreted toxins from Enteropathogenic Escherichia coli (EPEC). Mol. Cell. Probes 27, 200-207. doi: 10.1016/j.mcp.2013.06.004

Pacheco, A. R., and Sperandio, V. (2012). Shiga toxin in enterohemorrhagic E.coli: regulation and novel anti-virulence strategies. Front. Cell. Infect. Microbiol. 2:81. doi: 10.3389/fcimb.2012.00081

Palace, S. G., Proulx, M. K., Szabady, R. L., and Goguen, J. D. (2018). Gain-offunction analysis reveals important virulence roles for the yersinia pestis type iii secretion system effectors YopJ, YopT, and YpkA. Infect. Immun. 86, 1-11. doi: 10.1128/IAI.00318-18

Pearson, J. S., Giogha, C., Mühlen, S., Nachbur, U., Pham, C. L. L., Zhang, Y., et al. (2017). EspL is a bacterial cysteine protease effector that cleaves RHIM proteins to block necroptosis and inflammation. Nat. Microbiol. 2:258. doi: $10.1038 /$ nmicrobiol.2016.258

Petty, N. K., Bulgin, R., Crepin, V. F., Cerdeño-Tárraga, A. M., Schroeder, G. N. Quail, M. A., et al. (2010). The citrobacter rodentium genome sequence reveals convergent evolution with human pathogenic Escherichia coli. J. Bacteriol. 192, 525-538. doi: 10.1128/JB.01144-09

Petty, N. K., Feltwell, T., Pickard, D., Clare, S., Toribio, A. L., Fookes, M., et al. (2011). Citrobacter rodentium is an unstable pathogen showing evidence of significant genomic flux. PLoS Pathog. 7:2018. doi: 10.1371/journal.ppat.1002018

Popa, C., Coll, N. S., Valls, M., and Sessa, G. (2016). Yeast as a heterologous model system to uncover type iii effector function. PLoS Pathog. 12:5360. doi: 10.1371/journal.ppat.1005360

Sabbagh, C. R. R., Carrere, S., Lonjon, F., Vailleau, F., Macho, A. P., Genin, S., et al. (2019). Pangenomic type III effector database of the plant pathogenic Ralstonia spp. PeerJ. 2019:e7346. doi: 10.7717/peerj.7346

Samudrala, R., Heffron, F., and McDermott, J. E. (2009). Accurate prediction of secreted substrates and identification of a conserved putative secretion signal for type III secretion systems. PLoS Pathog. 5:e1000375. doi: 10.1371/journal.ppat.1000375

Sandu, P., Crepin, V. F., Drechsler, H., McAinsh, A. D., Frankel, G., and Berger, C. N. (2017). The enterohemorrhagic Escherichia coli effector EspW triggers actin remodeling in a Rac1-dependent manner. Infect. Immun. 85, e00244-e00217. doi: 10.1128/IAI.00244-17

Serapio-Palacios, A., and Finlay, B. B. (2020). Dynamics of expression, secretion and translocation of type III effectors during enteropathogenic Escherichia coli infection. Curr. Opin. Microbiol. 54, 67-76. doi: 10.1016/j.mib.2019.12.001

Shenoy, A. R., Furniss, R. C. D., Goddard, P. J., and Clements, A. (2018). Modulation of host cell processes by T3SS effectors. Curr. Top. Microbiol. Immunol. 416, 73-115. doi: 10.1007/82_2018_106

Simmons, C. P., Goncalves, N. S., Ghaem-Maghami, M., Bajaj-Elliott, M., Clare, S., Neves, B., et al. (2002). Impaired resistance and enhanced pathology during infection with a noninvasive, attaching-effacing enteric bacterial pathogen, 
citrobacter rodentium, in mice lacking IL-12 or IFN- $\gamma$. J. Immunol. 168, 1804-1812. doi: 10.4049/jimmunol.168.4.1804

Slater, S. L., Sågfors, A. M., Pollard, D. J., Ruano-Gallego, D., and Frankel, G. (2018). The type III secretion system of pathogenic Escherichia coli. Curr. Top. Microbiol. Immunol. 416, 51-72. doi: 10.1007/82_2018_116

Teper, D., Burstein, D., Salomon, D., Gershovitz, M., Pupko, T., and Sessa, G. (2016). Identification of novel Xanthomonas euvesicatoria type III effector proteins by a machine-learning approach. Mol. Plant Pathol. 17, 398-411. doi: $10.1111 / \mathrm{mpp} .12288$

Tobe, T., Beatson, S. A., Taniguchi, H., Abe, H., Bailey, C. M., Fivian, A., et al. (2006). An extensive repertoire of type III secretion effectors in Escherichia coli $\mathrm{O} 157$ and the role of lambdoid phages in their dissemination. Proc. Natl. Acad. Sci. U.S.A. 103, 14941-14946. doi: 10.1073/pnas.0604891103

Vallance, B. A., Deng, W., Jacobson, K., and Finlay, B. B. (2003). Host susceptibility to the attaching and effacing bacterial pathogen Citrobacter rodentium. Infect. Immun. 71, 3443-3453. doi: 10.1128/IAI.71.6.3443-3453.2003

Vinatzer, B. A., Jelenska, J., and Greenberg, J. T. (2005). Bioinformatics correctly identifies many type III secretion substrates in the plant pathogen Pseudomonas syringae and the biocontrol isolate P. fluorescens SBW25. Mol. Plant-Microbe Interact. 18, 877-888. doi: 10.1094/MPMI-18-0877

Wagner, S., Grin, I., Malmsheimer, S., Singh, N., Torres-Vargas, C. E., and Westerhausen, S. (2018). Bacterial type III secretion systems: A complex device for the delivery of bacterial effector proteins into eukaryotic host cells. FEMS Microbiol. Lett. 365, 1-13. doi: 10.1093/femsle/fny201

Watson, J. L., Sanchez-Garrido, J., Goddard, P. J., Torraca, V., Mostowy, S., Shenoy, A. R., et al. (2019). Shigella sonnei O-antigen inhibits internalization, vacuole escape, and inflammasome activation. MBio 10, 1-14. doi: $10.1128 / \mathrm{mBio} .02654-19$

WHO (2015). WHO Estimates of the Global Burden of Foodborne Diseases. Geneva: WHO Press.

Wong, J. L. C., Romano, M., Kerry, L. E., Kwong, H.-S., Low, W.W., Brett, S. J., et al. (2019). OmpK36-mediated Carbapenem resistance attenuates ST258 Klebsiella pneumoniae in vivo. Nat. Commun. 10:3957. doi: $10.1038 /$ s41467-019-11756-y
Xu, Y., Bai, X., Jin, Y., Hu, B., Wang, H., Sun, H., et al. (2017). High prevalence of virulence genes in specific genotypes of atypical enteropathogenic Escherichia coli. Front. Cell. Infect. Microbiol. 7:109. doi: 10.3389/fcimb.2017.00109

Xue, L., Tang, B., Chen, W., and Luo, J. (2019). DeepT3: Deep convolutional neural networks accurately identify Gram-negative bacterial type III secreted effectors using the N-Terminal sequence. Bioinformatics 35, 2051-2057. doi: 10.1093/bioinformatics/bty931

Zhang, L., Chaudhuri, R. R., Constantinidou, C., Hobman, J. L., Patel, M. D., Jones, A. C., et al. (2004). Regulators encoded in the Escherichia coli type III secretion system 2 gene cluster influence expression of genes within the locus for enterocyte effacement in enterohemorrhagic $E$. coli O157:H7. Infect. Immun. 72, 7282-7293. doi: 10.1128/IAI.72.12.7282-729 3.2004

Zhang, X., McDaniel, A. D., Wolf, L. E., Keusch, G. T., Waldor, M. K., and Acheson, D. W. K. (2000). Quinolone antibiotics induce shiga toxin-encoding bacteriophages, toxin production, and death in mice. J. Infect. Dis. 181, 664-670. doi: $10.1086 / 315239$

Zheng, Y., Valdez, P. A., Danilenko, D. M., Hu, Y., Sa, S. M., Gong, Q., et al. (2008). Interleukin-22 mediates early host defense against attaching and effacing bacterial pathogens. Nat. Med. 14, 282-289. doi: 10.1038/n $\mathrm{m} 1720$

Conflict of Interest: The authors declare that the research was conducted in the absence of any commercial or financial relationships that could be construed as a potential conflict of interest.

The handling editor declared a past collaboration with the author GF.

Copyright $\odot 2020$ Slater and Frankel. This is an open-access article distributed under the terms of the Creative Commons Attribution License (CC BY). The use, distribution or reproduction in other forums is permitted, provided the original author(s) and the copyright owner(s) are credited and that the original publication in this journal is cited, in accordance with accepted academic practice. No use, distribution or reproduction is permitted which does not comply with these terms. 